makers should consider acupuncture as an adjunct to usual care for patients with persistent low back pain or migraine: the best evidence shows that the associated health gain represents good value.

\section{David Wonderling senior health economist}

(dwonderling@rcseng.ac.uk)

National Collaborating Centre for Acute Care, Royal College of Surgeons of England, London WC2A 3PE

Competing interests: None declared.

1 Maniadakis N, Gray A. The economic burden of back pain in the UK. Pain 2000;84:95-103.

2 Ratcliffe J, Thomas KJ, MacPherson H, Brazier J. A randomised controlled trial of acupuncture care for lower back pain: cost effectiveness analysis. BMJ 2006 doi: $10.1136 /$ bmj. $38932.806134 .7 \mathrm{C}$.

3 Thomas KJ, MacPherson H, Thorpe L, Brazier J, Fitter M, Campbell MJ, et al. Randomised controlled trial of a short course of traditional acupuncture compared with usual care for persistent non-specific low back pain. BMJ 2006 doi: $10.1136 / \mathrm{bmj} .38878 .907361 .7 \mathrm{C}$.
4 National Institute for Health and Clinical Excellence. Guide to the methods of technology appraisal. London: NICE, 2004. www.nice.org.uk/ page.aspx?o = 201973 (last accessed 31 Aug 2006)

5 RafteryJ.NICE: faster access to modern treatments? Analysis of guidance on health technologies. BMJ 2001;323:1300-3.

6 Canter PH, Thompson Coon J, Ernst E. Cost-effectiveness of complementary treatments in the United Kingdom: systematic review. BMJ 2005;331:880-1.

7 White AR, Ernst E. Economic analysis of complementary medicine: a systematic review. Complement Ther Med 2000; 8:;111-8.

8 Wonderling D, Vickers AJ, Grieve R, McCartney R. Cost effectiveness analysis of a randomised trial of acupuncture for chronic headache in primary care $B M J 2004$. 298 .

primary care. BMJ 2004;328:747-52.

óbjartsson A, Gøtzsche PC. Placebo interventions for all clinical conditions. Cochrane Database Syst Rev 2004;(2):CD003974.

10 Hoffman GA, Harrington A, Fields HL. Pain and the placebo: what we have learned. Perspect Biol Med 2005;48:248-65.

11 Furlan AD, van Tulder MW, Cherkin DC, Tsukayama H, Lao L, Koes BW, et al. Acupuncture and dry-needling for low back pain. Cochrane Database Syst Rev 2005;(1):CD001351.

12 Melchart D, Streng A, Hoppe A, Brinkhaus B, Witt C, Wagenpfeil S, et al. Acupuncture in patients with tension-type headache: randomised controlled trial. $B M J$ 2005;331:376-82.

13 Vincent C. The safety of acupuncture. BMJ 2001;323:467-8.

doi $10.1136 /$ bmj.38954.627361.BE

\title{
Childhood pneumonia in developing countries
}

\section{Refinement of clinical algorithms is a priority}

$\mathrm{D}$ espite major advances in our understanding of the burden and epidemiology of childhood acute respiratory infections, almost two million children still die from pneumonia each year, accounting for $20 \%$ of deaths in children aged under 5 years globally. ${ }^{2}$ Accurate figures are difficult to obtain, but the estimated incidence of pneumonia is 151 million new cases a year, and, of these, some 11-20 million $(7-13 \%)$ are severe enough to require hospitalisation. ${ }^{2}$ These composite figures do not reflect the tremendous inequity both between and within countries, with the bulk of pneumonia deaths affecting the poor with limited access to services. ${ }^{3}$

The crucial first step in tackling childhood pneumonia is being able to diagnose it accurately, a challenge highlighted in this week's $B M J$ by Hazir and colleagues. ${ }^{4}$ They analysed 1848 chest radiographs of children in Pakistan hospital outpatient settings who had had non-severe pneumonia diagnosed clinically according to World Health Organization guidelines. Only $14 \%$ of the children had radiological evidence of pneumonia. Other community studies in Pakistan have found chest radiographs to have very low specificity for pneumonia in young children. ${ }^{5}$

It is now almost 15 years since the launch of a global acute respiratory infection programme by WHO, which focused on simplified syndromic diagnosis of childhood pneumonia by health workers and management of selected cases with oral co-trimoxazole. ${ }^{6}$ Subsequent progress has focused on scaling up the management strategies by training health workers and inclusion of the strategies within the integrated management of childhood illnesses programmes. ${ }^{\mathrm{w1}}$ There have been several modifications of these diagnostic algorithms since and, with the emergence of antimicrobial resistance among common respiratory pathogens, ${ }^{7}$ an understandable spate of alternative treatment regimens. ${ }^{89}$ Given that many poor families in developing countries are unable to access services in health facilities, it is not surprising that the bulk of childhood pneumonia deaths occur in community settings where there are relatively few skilled health workers. There is emerging evidence that management of pneumonia in community settings by community health workers may reduce mortality significantly, ${ }^{10}$ and several pilot studies have confirmed the feasibility of such approaches. ${ }^{\text {w2-w4 }}$ Not surprisingly, there is considerable pressure to scale up these interventions in community settings, ${ }^{11}$ but their success will depend on the availability and application of robust diagnostic algorithms by health workers with only basic training or even lay people.

Radiology and determination of hypoxia by pulse oximetry have been considered the optimal methods for diagnosing pneumonia, ${ }^{w 5}$ but they are clearly suitable only for use in institutional settings. This immediately raises concerns as to the robustness of pneumonia diagnosis using clinical criteria. Although the low specificity of clinical algorithms may be unavoidable given the need to detect and diagnose pneumonia rapidly in young children, this can have unexpected consequences once such diagnostic methods are applied on a large scale, especially by community health workers. Others have also highlighted the importance of standardisation and supervision of health workers in their use of diagnostic criteria for pneumonia surveillance and management. ${ }^{\mathrm{w4} \text { w6 }}$

There are legitimate concerns that, once treatment regimens are rolled out for pneumonia management by community health workers, existing diagnostic criteria would lead to considerable overtreatment of children with respiratory infections. Given the paucity of effective and inexpensive antimicrobial agents for treating pneumonia, large scale use of existing agents for non-bacterial pneumonia significantly increases the risk of development of antimicrobial resistance. Clinical failure rates as high as $22 \%$ have been

Extra references $w 1-w 7$ are on bmj.com

Research p 629

$\longrightarrow$ 
reported among children treated with double dose co-trimoxazole for non-severe pneumonia, ${ }^{12}$ indicating that the problem already exists. Recent data on the failure of standard antimicrobial treatment with parenteral penicillin or amoxicillin for severe pneumonia among HIV infected children in Africa are even more alarming, with failure rates of $24 \%$ by day $14 .^{13}$

What then is the way forward? Clearly further refinement of clinical algorithms for easy diagnosis of childhood pneumonia by community health workers is necessary. This work is hampered by the lack of a gold standard for the diagnosis of pneumonia in population settings. Transthoracic lung aspiration and microbiology have been recommended for research work, ${ }^{\text {w7 }}$ but there is an urgent need to develop robust molecular methods for diagnosing pneumonia in the field. Given the planned large scale demonstration projects of Hib and pneumococcal conjugate vaccine in various parts of the world, development and validation of such diagnostic methods and clinical algorithms must become a priority. The large scale introduction of management strategies for pneumonia by community health workers must also be accompanied by robust monitoring and evaluation of the validity and impact of such strategies.

Zulfiqar A Bhutta Husein Lalji Dewraj professor and chairman

(zulfiqar.bhutta@aku.edu)

Department of Paediatrics and Child Health, Aga Khan University, Karachi, Pakistan
1 Bryce J, Boschi-Pinto C, Shibuva K, Black RE for the WHO Child Health Epidemiology Reference Group. WHO estimates of the causes of death in children. Lancet 2005;365:1147-52

2 Rudan I, Tomaskovic L, Boschi-Pinto C, Campbell H for the WHO Child Health Epidemiology Reference Group. Global estimate of the incidence of clinical pneumonia among children under five years of age. Bull World Health Organ 2004;82:895-903.

3 Williams BG, Gouws E, Boschi-Pinto C, Bryce J, Dye C. Estimates of world-wide distribution of child deaths from acute respiratory infections. Lancet Infect Dis 2002;2:25-32.

4 Hazir T, Bin Nisar Y, Qazi SA, Khan SF, Raza M, Zameer S, et al. Chest radiography in children aged 2-59 months diagnosed with non-severe pneumonia as defined by the World Health Organization: descriptive multicentre study in Pakistan. BMJ 2006; doi: 10.1136/ bmj.38915.673322.80

5 Nizami SQ, Bhutta ZA, Hasan R, Husen YA. Role of chest X-ray in the diagnosis of lower respiratory tract infections in children less than five years of age in community. PakJ Med Sci 2005;21:471-21.

6 World Health Organization. Antibiotics in the treatment of acute respiratory infections in young children. Geneva: WHO, 1990. (WHO/ARI/90.10.)

7 Klugman KP, Lonks JR. Hidden epidemic of macrolide resistant pneumococci. Emerg Infect Dis 2005;11:802-7.

8 Qazi S. Short-course therapy for community-acquired pneumonia in paediatric patients. Drugs 2005;65:1179-92.

9 Peltola H, Vuori-Holopainen E, Kallio MJ, for the SE-TU Study Group. Successful shortening from seven to four days of parenteral beta-lactam treatment for common childhood infections: a prospective and randomized study. Int J Infect Dis 2001;5:3-8.

10 Sazawal S, Black RE, for the Pneumonia Case Management Trials Group Effect of pneumonia case management on mortality in neonates, infants, and preschool children: a meta-analysis of community-based trials. Lanand preschool children: a

11 United Nations Children's Fund, World Health Organization. WHO UNICEF joint statement. Management of pmeumonia in community settings. Geneva: WHO, 2004. (WHO/FCH/CAH/04.06.)

12 Rasmussen ZA, Bari A, Qazi S, Rehman G, Azam I, Khan S, et al. Randomized controlled trial of standard versus double dose cotrimoxazole for childhood pneumonia in Pakistan. Bull World Health Organ 2005;83:10-9.

13 Jeena P, Thea DM, MacLeod WB, Chisaka N, Fox MP, Coovadia HM, et al. Failure of standard antimicrobial therapy in children aged 3-59 months Failure of standard antimictil therapy in with mild or asymptomatic HIV infection and severe pneumonia. Bull
World Health Organ 2006;84:269-75.

doi $10.1136 / \mathrm{bmj} .38975 .602836 . \mathrm{BE}$

\section{Caesarean delivery in the second stage of labour}

\section{Better training in instrumental delivery may reduce rates}

$\mathrm{D}$ espite much discussion of the increase in elective caesarean rates over the past 20 years, w1 little attention has been paid to the rise in second stage caesarean section rates. The maternal risks of second stage caesareans include major haemorrhage, longer hospital stay, greater risk of bladder trauma, and extension tears of the uterine angle leading to broad ligament haematoma. ${ }^{2}$ Although second stage caesarean section is sometimes appropriate, many could be prevented by the attendance of a more skilled obstetrician.

Currently, obstetric trainees perform most of the second stage trials of instrumental delivery. A recent UK study found that decisions made by consultant obstetric staff are important in determining whether a second stage caesarean section is the optimum method of delivery for women with delay in advanced labour. ${ }^{3}$ The investigators found substantial differences between consultants' and specialist registrars' opinions on factors affecting safe vaginal delivery-such as position of the fetal head in the maternal pelvis and its proximity to the pelvic outlet. Consequently, a consultant obstetrician who performed a vaginal assessment was more likely to reverse a decision made by an obstetric trainee for a caesarean and proceed to a
From the women's perspective, receiving a senior opinion might make their labour worth while, in that they have a successful vaginal birth, and their delivery and reproductive future safer. Without increases in junior doctors' experience and recruitment into the specialty, the problems with second stage caesareans will rise. Furthermore, women who have undergone a caesarean section are less likely to have a vaginal birth in subsequent pregnancies because they tend to request repeat elective caesarean delivery. ${ }^{4}$ Repeat and recurrent caesareans are associated with higher rates of placenta praevia and accreta. ${ }^{5 \mathrm{w} 2 \mathrm{w} 3}$

According to the Royal College of Obstetricians and Gynaecologists audit figures, about 35\% of caesareans for singleton pregnancies are performed because of failure to progress in labour, of which a quarter occur at full cervical dilatation. ${ }^{6}$ In $55 \%$ of these cases no attempt was made to achieve a vaginal birth with either forceps or ventouse. In those births where instrumental delivery was attempted, the audit noted a "failed" rate of $35 \%$ for ventouse and $2 \%$ for forceps. These figures are in keeping with the known higher risk of failure associated with ventouse and a gradual decline in the use of forceps. There is an understand-

Extra references w1-w5 are on bmj.com 